\title{
REAÇÃO DE CULTIVARES DE COENTRO AO NEMATOIDE DAS GALHAS
}

Guilherme Matos Martins Diniz"; ; José Luiz Sandes de Carvalho Filho²; Luiz Antônio Augusto Gomes³; Cleiton Lourenço de Oliveira4; Wantuir Filipe Teixeira Chagas ${ }^{5}$; Lucas da Silva Santos ${ }^{1}$

\footnotetext{
${ }^{1}$ Doutor em Agronomia (Genética e melhoramento de plantas), Departamento de Produção Vegetal, Universidade Estadual de São Paulo (UNESP), Via de Acesso Prof. Paulo Donato Castellane s/n 14884-900 - Jaboticabal, SP.

${ }^{2}$ Professor do Departamento de Agronomia, Universidade Federal Rural de Pernambuco

Rua Dom Manuel de Medeiros, s/n, Dois Irmãos - CEP: 52171-900 - Recife/PE

${ }^{3}$ Professor do Departamento de Agricultura, Universidade Federal de Lavras, Câmpus Universitário, Caixa Postal 3037, CEP 37200$000 \cdot$ Lavras/MG.

${ }^{4}$ Doutor em Fitotecnia, Departamento de Agricultura, Universidade Federal de Lavras, Câmpus Universitário, Caixa Postal 3037, CEP 37200-000 • Lavras/MG.

${ }^{5}$ Doutor em Ciência do Solo, Departamento de Solos, Universidade Federal de Lavras, Câmpus Universitário, Caixa Postal 3037, CEP 37200-000 • Lavras/MG.
}

*Autor para correspondência: guilhermedinizzz@hotmail.com

\begin{abstract}
RESUMO: 0 controle do nematoide das galhas em diversas culturas tem sido feito com a utilização de produtos químicos. Porém, a utilização de cultivares resistentes para diversas espécies de hortaliças tem mostrado ser uma importante alternativa no controle deste patógeno. 0 objetivo dessa pesquisa foi de avaliar a reação de cultivares de coentro para resistência a Meloidogyne incognita, raças 1 e 3, e M. javanica. $O$ experimento foi conduzido em casa de vegetação nas dependências da HortiAgroß Sementes Ltda., em ljaci, MG, de outubro a dezembro de 2011. Foram avaliadas seis cultivares de coentro: Português, Tabocas, Tapacurá, Verdão, Palmeira e HTV-9299, em três tipos de inóculo, $M$. incognita, raças 1 e 3, e M. javanica. 0 delineamento experimental foi em blocos casualizados, com seis repetições para cada inóculo. Foram avaliadas as características: número de galhas e de massa de ovos, número de ovos e fator de reprodução (FR). A partir dos valores de FR obtidos, avaliou-se a reação das cultivares, em que $F R \leq 1,0=$ hospedeiro resistente a $M$. incognita, raças 1 e 3 , e $M$. javanica. Todas as cultivares foram suscetíveis a $M$. incognita raça 1 e resistentes a $M$. incognita raça 3 e $M$. javanica.
\end{abstract}

PALAVRAS-CHAVE: Coriandrum sativum, Meloidogyne spp., resistência.

\section{REACTION OF CULTIVARS OF CORIANDER TO ROOT KNOT NEMATODE}

\begin{abstract}
The control of the root knot in several crops has been done with the use of chemicals. However, the use of resistant cultivars for several species of vegetable has been shown to be an important alternative in the control of this pathogen. The objective of this research was to evaluate the reaction of coriander cultivars for resistance to Meloidogyne incognita, races 1 and 3, and M. javanica. The experiment was carried out in a greenhouse at HortiAgro@ Sementes Ltda., In ljaci, MG, from October to December 2011. Six cultivars of coriander were evaluated: Portuguese, Tabocas, Tapacurá, Verdão, Palmeira and HTV-9299, in three types of inoculum, M. incognita, races 1 and 3 , and $M$. javanica. The experimental design was in randomized blocks, with six replicates for each inoculum. The following characteristics were evaluated: number of galls and egg mass, number of eggs and reproduction factor (RF). From the obtained FR values, the reaction of the cultivars was evaluated, where FR $\leq 1.0=$ host resistant to $M$. incognita, races 1 and 3 , and $M$. javanica. All cultivars were susceptible to $M$. incognita race 1 and resistant to $M$. incognita race 3 and $M$. javanica.
\end{abstract}

KEYWORDS: Coriandrum sativum, Meloidogyne spp., Resistance.

\section{INTRODUÇÃO}

$O$ coentro (Coriandrum sativum L.), pertencente à família Apiaceae, foi introduzido no Brasil no início do século XVI, pelos colonizadores portugueses. Produz folhas e frutos aromáticos, sendo um dos temperos básicos para os pratos salgados da cozinha das regiões 
Norte e Nordeste do Brasil (Nascimento e Pereira, 2005). As folhas e os frutos do coentro apresentam propriedades carminativas e estomáquicas, sendo 0 fruto registrado para fins farmacêuticos (Costa, 2002).

Ainda são poucos os trabalhos com melhoramento genético, de modo que as cultivares disponíveis estão sendo utilizadas em várias regiões geográficas, sem que se considere suas possíveis diferenças de desenvolvimento nos diversos ambientes (Melo, 2009), porém, alguns estudos têm sido desenvolvidos para o coentro nas áreas de nutrição mineral (Alves et al., 2005; Oliveira et al., 2006), transmissão de patógenos (Reis et al., 2006), desenvolvimento de novas cultivares (Pereira et al., 2005) e estudo da variabilidade genética (Melo et al., 2009). Apesar disso, poucas cultivares de coentro estão disponíveis aos produtores e, em algumas regiões, são utilizadas cultivares locais, de origem desconhecida, cujas sementes são produzidas pelos próprios agricultores (Pereira, 2005).

Aocorrência de nematoide de galha, comum em áreas destinadas ao cultivo de olerícolas, vem causando perdas econômicas pela queda de produtividade em razão dos danos no sistema radicular (Rosa et al., 2013; Pinheiro et al., 2014). 0 gênero Meloidogyne Goeldi, 1887, possui cerca de 90 espécies descritas e mais de 2000 espécies vegetais hospedeiras (Hunt e Handoo, 2009), compreendendo espécies frutícolas, ornamentais e olerícolas (Bitencourt e Silva, 2010), sendo as espécies $M$. incognita e $M$. javanica, de maior ocorrência no Brasil e no mundo (Da Silva et al., 2011).

A prática mais usual no controle de fitonematoides das galhas em diversas culturas tem sido a utilização de produtos químicos, porém, estes são altamente tóxicos e de elevada capacidade residual, causando problemas à saúde e ao meio ambiente sendo que, além disso, não existem produtos para controle deste fitopatógeno registrados para 0 coentro (Maluf, 1997, Pinheiro et al., 2016).

Um método viável para controle de nematoides é a utilização de cultivares resistentes, (Kanayama et al., 2009; Queiróz et al., 2014). Existem trabalhos com outras hortaliças para caracterização de cultivares quanto à resistência a nematoides, (Carvalho Filho et al., 2007; Ferreira et al., 2013; Oliveira et al., 2015), porém, são escassos os trabalhos com caracterização da resistência de coentro a $M$. incognita e $M$. javanica. Para a produção de coentro, os cultivares presentes no mercado possuem excelente aceitação, porém ainda não foram avaliadas para resistência a nematoides. A cultivar Português possui ciclo de 50 a 60 dias, com folhas verdes escuras e resistência ao pendoamento precoce; a cultivar Tabocas tem ciclo de 35 a 40 dias, plantas uniformes de excelente rusticidade, folhas grandes e pouco recortadas, coloração verde escuro, boa tolerância ao pendoamento precoce, além de boa adaptação às regiões Norte, Nordeste e Centro Oeste do Brasil; Tapacurá tem ciclo de 40 a 50 dias, porte baixo entre 25 e $30 \mathrm{~cm}$, talos grossos e resistentes, excelente rendimento por área, folhas grandes, prostradas e pouco recortadas e alta tolerância ao pendoamento precoce; A cultivar Verdão é bastante precoce com ciclo de 30 a 40 dias, apresenta planta muito vigorosa, folhas na coloração verde-escura, excelente rusticidade e boa resistência às doenças de folhagens; a cultivar Palmeira apresenta ciclo de 50 a 60 dias e folhas verde-escuras; cultivar HTV-9299 é ainda uma cultivar nova em fase de avaliações, mostrando resultados promissores para 0 mercado.

A utilização de cultivares resistentes para diversas espécies de olerícolas tem-se mostrado uma importante alternativa no controle deste patógeno (Maluf, 1997), sendo o método mais viável, segundo alguns autores (Kanayama et al., 2009; Ferreira et al., 2010), não elevando o custo de produção, exceto pela compra da própria semente.

Dessa forma, torna-se viável proceder ao melhoramento genético na cultura do coentro visando a obtenção de novas cultivares, já que, atualmente, a utilização de cultivares em áreas infestadas torna-se difícil pela falta de cultivares resistentes que atendam às exigências do mercado. Assim, foram realizados três ensaios independentes para caracterizar cultivares comerciais de coentro quanto a resistência a $M$. incognita (raças 1 e 3) e $M$. javanica.

\section{MATERIAL E MÉTODOS}

Os ensaios foram realizados, simultaneamente, no período de outubro a dezembro de 2011 em estufa nas dependências do Centro de Desenvolvimento e Transferência de Tecnologia da Universidade Federal de Lavras, junto à Hortiagro Sementes S/A, em ljaci, $M G$, localizado na região Sul do Estado de Minas Gerais, a $21^{\circ} 10^{\prime}$ latitude Sul e $44^{\circ} 55^{\prime}$ longitude Oeste, em uma altitude de 832 metros. A temperatura média anual é de $19,4^{\circ} \mathrm{C}$, com médias mínimas de $14,8^{\circ} \mathrm{C}$ e médias máximas de $26,1^{\circ} \mathrm{C}$. 
0 delineamento experimental para cada experimento foi 0 de blocos casualizados, com seis repetições e parcelas de 16 plantas.

A semeadura dos genótipos de coentro foi realizada em bandejas de poliestireno expandido, de 128 células contendo seis sementes (três frutos) por célula e substrato comercial organomineral Plantmax. Após a emergência, quando as plântulas apresentavam a primeira folha definitiva, procedeu-se ao desbaste, deixando-se apenas uma plântula por célula.

Adicionalmente em cada bandeja, duas fileiras foram semeadas com tomateiro cultivar Santa Clara, suscetível a Meloidogyne spp. Estas plantas de tomateiro foram utilizadas para se verificar a viabilidade do inóculo, mediante a constatação da formação de galhas nas raízes. Os ovos de $M$. incognita raças 1 e $3 \mathrm{e}$ de M. javanica utilizados como inóculo foram retirados de plantas de tomateiro infestados artificialmente com inóculo das espécies de Meloidogyne spp., oriundos do Centro de Desenvolvimento e Transferência de Tecnologia da Universidade Federal de Lavras, junto à Hortiagro Sementes S/A, em ljaci, MG de acordo com a técnica de Hussey e Barker (1973) modificada por Bonetti e Ferraz (1981), triturando as raízes e passandoas em jogo de peneiras com malha de 200 mesh de abertura sobreposta em peneira de 500 mesh, para obtenção dos ovos oriundos de uma única progênie pura do nematoide, mantida e multiplicada em plantas de tomateiro Santa Clara, em casa de vegetação da Universidade Federal de Lavras.

Decorridos 15 dias após a semeadura, procedeu-se a infestação do substrato com $M$. incognita raças 1 e 3 e $M$. javanica. 0 inóculo foi injetado com 0 auxílio de seringa de uso veterinário diretamente no substrato. Aplicou-se $1 \mathrm{~mL}$ de uma suspenção em concentração de 1.200 ovos. $\mathrm{mL}^{-1}$ ao lado de cada planta. Aos 45 dias após a inoculação pôde-se observar uma intensa formação de galhas e massas de ovos nas raízes do tomateiro, indicando ser este o momento para se iniciar as avaliações.

As plantas de coentro foram arrancadas e avaliadas, individualmente, para as características incidência de galhas, número de galhas, número de massas de ovos e número de ovos. Para determinação da incidência de galhas, cada planta, ainda com 0 torrão, teve o seu sistema radicular cuidadosamente observado utilizando-se a escala proposta como segue: 1 = 0 galhas; 2 = 1 a 2 galhas; 3 = 3 a 10 galhas; 4 =
11 a 30 galhas e $5=$ mais de 30 galhas por sistema radicular de acordo com Charchar et al. (2003).

Para determinação das características número de galhas e para número de massas de ovos, cada planta teve seu sistema radicular previamente submergido em água parada para o desprendimento do substrato. Em seguida, foram contados o número de galhas e o número de massas de ovos por sistema radicular e atribuídas as notas correspondentes. Para facilitar a visualização das massas de ovos após a lavagem das raízes, estas foram coloridas com corante usado na indústria alimentícia contendo bordeaux na concentração de 1\% (Rocha et al., 2005).

Para avaliação do número de galhas e massas de ovos, utilizou-se uma escala de notas (1 a 5), sendo: $1=$ sistema radicular com número de galhas $\leq 10 ; 2=$ sistema radicular com número de galhas $\geq 11 \mathrm{e} \leq 20 ; 3$ = sistema radicular com número de galhas $\geq 21$ e $\leq 30$; 4 = sistema radicular com número de galhas $\geq 31$ e $\leq$ 40; e 5 = sistema radicular com um número de galhas $\geq 40$ procedendo da mesma maneira para a avaliação da massa de ovos.

Para a avaliação do número de ovos, procedeuse à extração conforme técnica de Hussey e Barker (1973), modificada por Bonetti e Ferraz (1981). Os ovos foram contados em microscópio óptico e câmara de Peters, obtendo-se o número de ovos por planta de coentro (NOC), os quais corresponderam à população final (Pf) de nematoides. De posse desses dados, foi obtido o fator de reprodução (FR), dado pela razão entre a população final e inicial de ovos inoculados $(F R=P f / P i)$. De acordo com os valores de FR obtidos, determinou-se para cada ensaio a reação da cultivar pela escala de Oostenbrink (1966), em que FR = 0 (hospedeiro imune), FR $\leq 1,0$ (hospedeiro pouco resistente); $F R>1,0$ (hospedeiro suscetível).

A caracterização dos genótipos foi feita através da distribuição de frequência de classes para as características incidência de galhas, número de galhas, número de massa de ovos e número de ovos, observando-se as notas obtidas em cada cultivar para os inóculos de M. incognita (raças 1 e 3) e M. javanica.

\section{RESULTADOS E DISCUSSÃO}

Considerando as características incidência de galhas e número de massa de ovos, a maior frequência de plantas ficou com notas 1 e 2 em todas as cultivares 
(Figura 1). Em trabalhos sobre variabilidade em progênies de meios-irmãos de coentro, relatam que existe possibilidade de seleção de genótipos para várias características, a partir da variabilidade existente, o que pode ocorrer para resistência a nematoides. (Melo et al., 2009; Carvalho Filho et al., 2011).

Figura 1. Distribuição de frequência de classe para incidência de galhas, número de galhas, número de massas de ovos e número de ovos nas raízes das cultivares: Português (A), Tabocas (B), Tapacurá (C), Verdão (D), Palmeira (E) infectados por M. incognita raça 1, Lavras - MG, 2011.

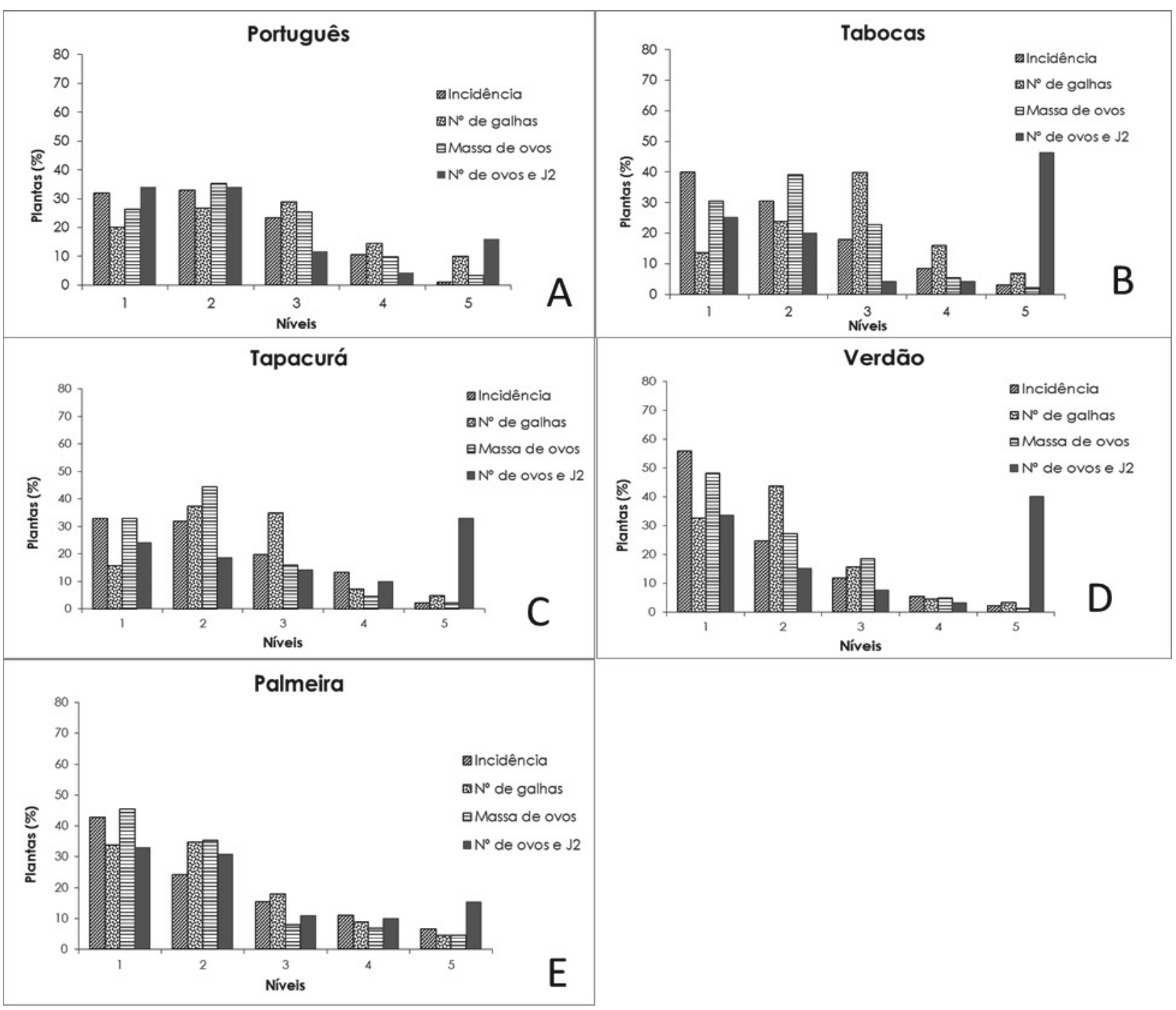

Para número de galhas, as cultivares tiveram o maior número de plantas para nota 2 com mais de $40 \%$ das plantas avaliadas (Figura 1). Trabalhos realizados com alface para observar a existência da interferência dos fitonematoides na fase de plântula demonstraram que essa interferência vai reduzindo ao longo do ciclo, observando redução na infecção e que, utilização de bandejas com células maiores permitiram 0 prolongamento do período de permanência das mudas no viveiro antes do transplantio, possibilitando uma diminuição nessa interferência (Santos et al., 2008). Esses resultados podem explicar os dados obtidos, possibilitando uma análise da forma de plantio utilizada atualmente em coentro, para uma posterior forma de manejo de fitonematoides.

Os valores superiores a 1,0 encontrados para multiplicação de $M$. incognita raça 1 baseados no fator de reprodução, confirmam a suscetibilidade das cultivares de coentro. Os valores inferiores a 1,0 encontrados para multiplicação de $M$. incognita raça 3 , confirmam a resistência das cultivares de coentro (Tabela 1). 
Tabela 1. Fator de reprodução e reação de cultivares de coentro, inoculados com ovos de e M. incognita raças1 e 3 e M. javanica, Lavras - MG, 2012

\begin{tabular}{lcccccc}
\hline Genótipos & Mi r1 & Reação & Mi r3 & Reaçãa & M. javanica & Reação $^{1}$ \\
\hline Português & 1,3 & $\mathrm{~S}$ & 0,8 & $\mathrm{R}$ & 0,5 & $\mathrm{R}$ \\
\hline Tabocas & 2,6 & $\mathrm{~S}$ & 0,8 & $\mathrm{R}$ & 0,5 & $\mathrm{R}$ \\
\hline Tapacurá & 2,2 & $\mathrm{~S}$ & 0,8 & $\mathrm{R}$ & 0,6 & $\mathrm{R}$ \\
\hline Verdão & 2,4 & $\mathrm{~S}$ & 0,7 & $\mathrm{R}$ & 0,5 & $\mathrm{R}$ \\
\hline Palmeira & 1,3 & $\mathrm{~S}$ & 0,8 & $\mathrm{R}$ & 0,5 & $\mathrm{R}$ \\
\hline HTV-9299 & - & - & 0,8 & $\mathrm{R}$ & 0,8 & $\mathrm{R}$ \\
\hline 2'Sta Cruz Kada' & 8,3 & $\mathrm{~S}$ & 8,6 & $\mathrm{~S}$ & 9.2 & $\mathrm{~S}$ \\
\hline
\end{tabular}

${ }^{1}$ Reação segundo escala proposta por Oostenbrink (1966) onde $R=$ hospedeiro resistente; $S=$ hospedeiro

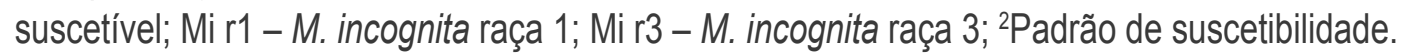

Para a distribuição de frequência as cultivares 'Português', 'Verdão' e 'Palmeira' foram as cultivares com maior frequência de plantas com nota 1 , apresentando valores superiores a $55 \%$ das plantas (Figura 2- A, D e E). De acordo com resultados encontrados para reação de cultivares de coentro a M. javanica a partir do fator de reprodução, todas as cultivares foram classificadas como resistentes ao nematoide diferindo dos resultados encontrados por Rosa et al., (2013) (Tabela 1).

Figura 2. Distribuição de frequência de classe para incidência de galhas, número de galhas, massa de ovos e número de ovos nas raízes de cultivares de coentro: Português (A), Tabocas (B), Tapacurá (C), Verdão (D), HTV9299 (E), Palmeira (F), infectadas por Meloidogyne incognita raça 3, Lavras - MG, 2011.

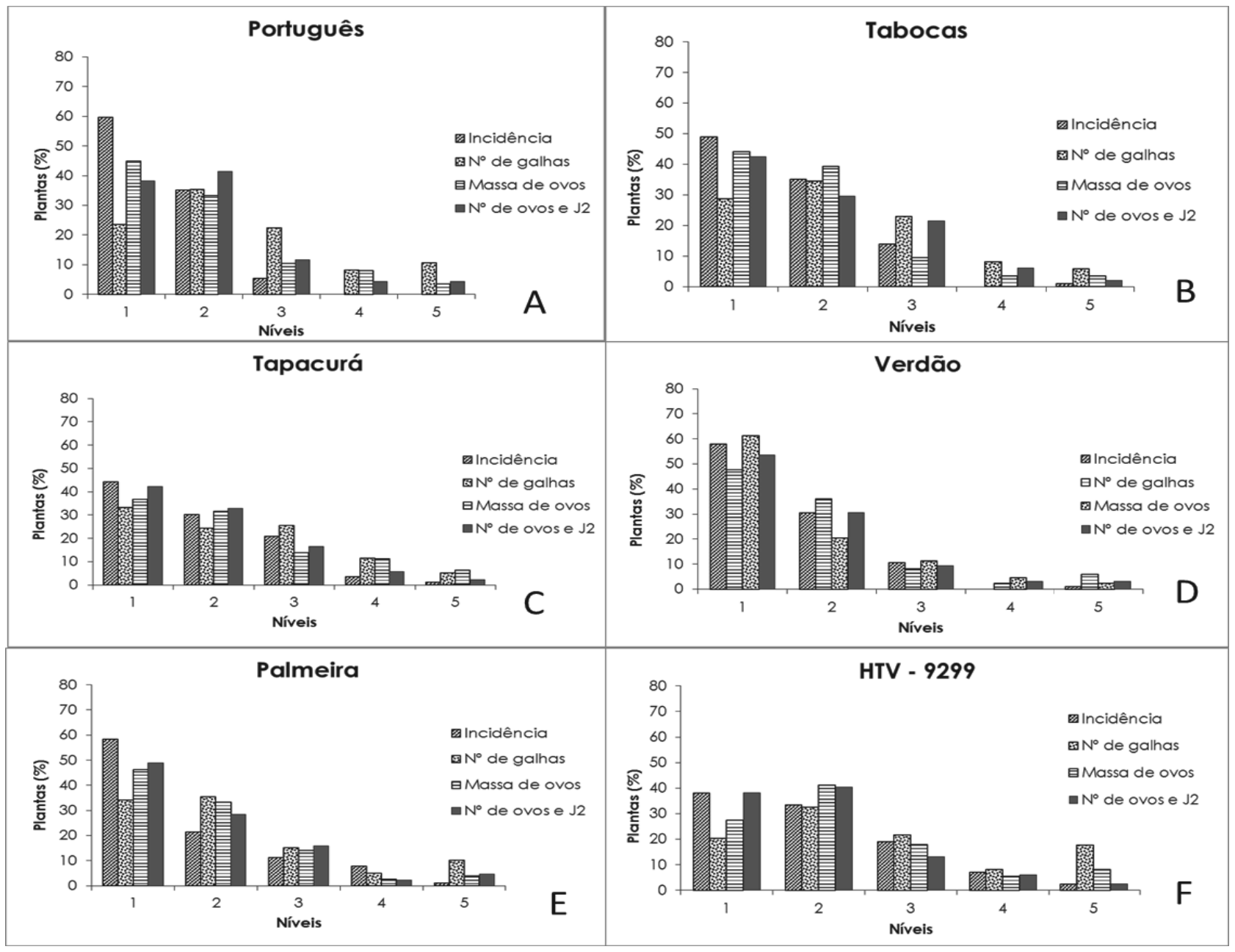


Pela distribuição de frequência das plantas para as cultivares quanto à resistência a M. javanica, observou-se uma tendência da frequência para as notas 1 e 2 (Figura 3). As cultivares 'Português',
'Tabocas' e 'Verdão' foram as cultivares com frequência maior de plantas com nota 1 apresentando valores maiores que $85 \%$ das plantas para incidência de galhas (Figura 3- A, B, D).

Figura 3. Distribuição de frequência de classe para incidência de galhas, número de galhas, massa de ovos e número de ovos nas raízes de cultivares de coentro: Português (A), Tabocas (B), Tapacurá (C), Verdão (D), Palmeira (E), HTV-9299 (F), infectadas por M. javanica, Lavras - MG, 2011.

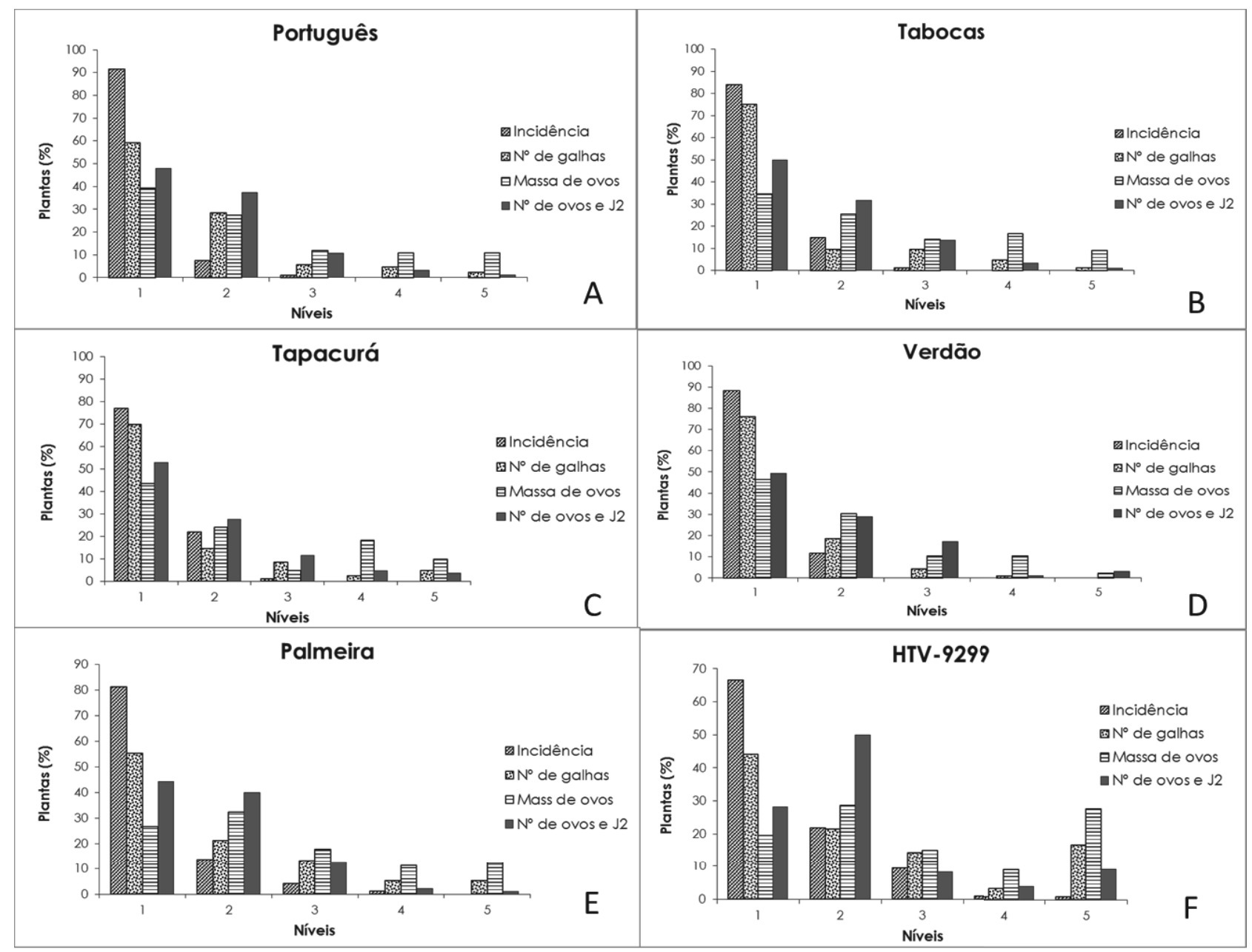

As plantas apresentaram número de massa de ovos com maior frequência de plantas para a nota 2. Para todas as características avaliadas, a maior frequência de plantas ficou com notas 1 e 2 em todas as cultivares (Figura 3). De acordo com a distribuição de frequência para a característica massa de ovos observa-se um maior número de plantas com nota 2 para as cultivares avaliadas (Figura 3).

Baseando-se na frequência de plantas para cada nota para índice de galhas, número de galhas, número de massa de ovos e número de ovos, relativos a cada uma das cultivares, foi observada uma distribuição menor para todas as características. Essa distribuição pode estar ligada a forma de cultivo da cultura durante o experimento, além do recipiente utilizado para cultivo. Comercialmente o coentro é produzido com semeadura direta no canteiro, possibilitando um contato maior com os nematoides presentes no solo, o que leva a danos mais expressivos nas plantas. No experimento, 0 contato da cultura do coentro com os nematoides deuse com a planta já em pleno crescimento, o que pode ter influenciado na multiplicação do nematoide durante seu ciclo.

Esses resultados podem ser utilizados em cultivos de coentro para produção de sementes em que o ciclo de produção é maior, além da utilização da área por vários ciclos consecutivos, possibilitando 0 aumento da densidade populacional do nematoide. 
Para a característica incidência de galhas todas as cultivares tiveram comportamento semelhante, com frequência das plantas com pouca incidência de galhas 0 que evidencia menores valores para essas características (Figura 3).

Para avaliação das cultivares quanto à frequência de plantas para cada nota relativa, observouse pouca variação na frequência de plantas na incidência de galhas (IG), número galhas (NG), número de massa de ovos (NMO) e número de ovos (NO) por sistema radicular entre as cultivares. Observou-se também que todas as cultivares que tiveram menor número de galhas também tiveram número reduzido de ovos, o que elevou a frequência de plantas com nota baixa para essas características (Figura 3).

Em populações de plantas alógamas, não há preocupação com o indivíduo e sim com a população. Dessa forma, a elevação na frequência de alelos resistentes na população reduzirá a quantidade de ovos e diminuirá os indivíduos suscetíveis na população. Todos os resultados demonstram que existe variabilidade mesmo dentro das cultivares de coentro, com genótipos apresentando diferentes níveis de resistência à $M$. incognita (raças 1 e 3 ) e $M$. javanica, mesmo em cultivares consideradas resistentes observou-se essa variabilidade (Figura 3). A seleção de genótipos com notas 1 e 2 para todos as características estudadas possibilitará ganhos genéticos, ou seja, 0 desenvolvimento de populações com maiores níveis de resistência.

Considerando a população, todas as cultivares foram suscetíveis a $M$. incognita raça 1 e resistentes a $M$. incognita raça 3 e $M$. javanica e a seleção de plantas com notas 1 e 2 dentro das cultivares para todas as características estudadas proporcionará ganhos genéticos e obtenção de cultivares com níveis de resistência superiores. A cultivar Verdão obteve os melhores resultados quanto à resistência à $M$. incognita (raças 1 e 3) e M. javanica podendo ser utilizadas em programas de melhoramento genético.

\section{REFERÊNCIAS BIBLIOGRÁFICAS}

Alves, E.U.; Oliveira, A.P.; Alcântara, R.L.; Sader, B.R.; Alves, A.U. Rendimento e qualidade fisiológica de sementes de coentro cultivado com adubação orgânica e mineral. Revista Brasileira de Sementes, 2005, 27, 132-137.
Bertini, C.H.C. de M.; Pinheiro, E.A.R.; Nóbrega, G.N.; de Lima Duarte, J.M. Desempenho agronômico e divergência genética de genótipos de coentro. Revista Ciência Agronômica, 2010, 41, 409-416.

Bitencourt, N.V.; Silva, G.S. Reprodução de Meloidogyne enterolobii em olerícolas. Nematologia Brasileira, 2010, $34,181-183$.

Boneti, J.I.S.; Ferraz, S. Modificação do método de Hussey \& Barker para extração de ovos de Meloidogyne exigua de raízes de cafeeiro. Fitopatologia Brasileira, $1981,6,3,553$.

Carvalho Filho, J.L.S.; Gomes, L.A.A.; Silva, R.R.; Ferreira, S.; Carvalho, R.R.C.; Maluf, W.R. Parâmetros populacionais e correlação entre características da resistência a nematoides de galhas em alface. Revista Brasileira de Ciências Agrárias, 2011, 1, 46-51.

Carvalho Filho, J.L.S.; Gomes, L.A.A.; Westerich, J.N.; Maluf, W.R.; Campos, V.P. Caracterização de famílias F4 de alface de folhas lisas quanto à homozigose para resistência à Meloidogyne incognita. Revista Brasileira de Agrociência, 2007, 13, 336-342.

Charchar, J.M., Giordano, L.B., Boiteux, L.S. Metodologia para seleção de hortaliças com resistência a nematoides: Famílias Convolvulaceae e Solanaceael Meloidogyne spp. Brasília: Embrapa Hortaliças, (Embrapa Hortaliças. Comunicado Técnico, 21), 2003, p. 4.

Costa, A.F. Farmacognosia. Lisboa: Fundation Calouste Gulbenkian, 2002, 6, 1031.

Silva, G.O.; Pinheiro, J.B.; Vieira, J.V.; Carvalho, A.D. Seleção para resistência de genótipos de cenoura aos nematóides-das-galhas. Horticultura brasileira, 2011, 29, 335-341.

Ferreira, S.; Gomes, L.A.A.; Gasparino, C.F.; Carvalho Filho, J.L.S. de.; Maluf, W.R. Caracterização de famílias F2:3 de alface para resistência ao nematoide das galhas. Revista Agrogeoambiental, 2013, 2, 35-42.

Freitas, L.G.; Oliveira, R.D.L.; Ferraz, S. Introdução à Nematologia. UFV, Viçosa. 2001, 83. 
Hunt, D.J.; Handoo, Z.A. "Taxonomy, identification, and principal species". In Roland N. Perry, Maurice Moens \& James L. Starr. Root-knot Nematodes. CAB International. 2009, 55-97.

Kanayama, F.S.; Sera, G.H.; Sera, T.; Mata, J.S. da.; Ruas, P.M.; Ito, D.S. Progênies de Coffea arabica cV. IPR 100 com resistência ao nematoide Meloidogyne incognita raça 1. Ciência e Agrotecnologia, 2009, 33, 1321-1326.

Maluf, W.R. Resistência a nematoides das galhas Meloidogyne spp. em espécies olerícolas. In: Zambolin, L.; Ribeiro-do-Vale, F. X. Resistência de Plantas a Doenças. Fitopatologia Brasileira, 1997, 30, 57-63.

Melo, R.A.; Menezes, D.; Resende, L.V.; Wanderley Júnor, L.J.G.; Melo, P.C.T.; Santos, V.F. Caracterização morfológica de genótipos de coentro. Horticultura Brasileira. 2009, 27, 371-376.

Nascimento, W. M.; Pereira, R. S. Coentro: a hortaliça de mil e uma utilidades. Horticultura Brasileira, 2005, 23, 371-376.

Oliveira, A.P.; Alves, E.U.; Alcâtara, R.L.; Sader, B.R.; Alves, A.U. Produção e qualidade fisiológica de sementes de coentro em função de doses de nitrogênio. Revista Brasileira de Sementes, 2006, 28, 193-198.

Oliveira, C.D.D.; Braz, L.T.; Santos, J.M.D.; Banzatto, D.A.; Oliveira, P.R.D. Resistência de pimentas a nematoides de galha e compatibilidade enxerto/ porta-enxerto entre híbridos de pimentão e pimentas. Horticultura Brasileira, 2009, 27, 520-526.

Oliveira, G.H.F.; Santana, S.E.R.E.A.; Fonseca, R.C.N.; de Lima, L.E.; Gomes, L.A.A.; de Carvalho Filho, J.E.L.S. Meloidogyne incognita resistant strains of leaf lettuce. African Journal of Agricultural Research, 2015, 10: $4660-4667$.

Oostenbrink, M. Major characteristics of the relation between nematodes and plant. Meded. Landbouw. $1966,66,1-46$.
Pereira, R.S.; Muniz, M F.B.; Nascimento, W.M. Aspectos relacionados à qualidade de sementes de coentro. Horticultura Brasileira, 2005, 23, 703-706.

Pinheiro, J.B.; Reifschneider, F.J.; Pereira, R.B.; Moita, A.W. Reação de genótipos de Capsicum ao nematoidedas-galhas. Horticultura Brasileira, 2014, 32, 371-375.

Pinheiro, J.B.; Pereira, R.B. Manejo de nematoides na cultura do coentro e salsinha. Brasília, DF: Embrapa, 2016. 8 p. (Embrapa Hortaliças. Circular Técnica, 149). Disponível em:< http://info.cnptia.embrapa.br/digital/ bitstream/ item/145870/1/CT-149.pdf >.

Queiróz, C.D.A.; Fernandes, C.D.; Verzignassi, J.R.; Valle, C.B.D.; Jank, L.; Mallmann, G.; Batista, M.V. Reaction of accessions and cultivars of Brachiaria spp. and Panicum maximum to Pratylenchus brachyurus. Summa Phytopathologica, 2014, 40, 226-230.

Reis, A.; Satelis, J.F.; Pereira, R.S.; Nascimento, W.M. Associação de Alternaria dauci e A. alternata com sementes de coentro e eficiência do tratamento químico. Horticultura Brasileira, 2006, 24, 107-111.

Rocha, F.S.; Muniz, M.F.S.; Campos, V.P. Coloração de fitonematoides com corantes usados na indústria alimentícia brasileira. Nematologia Brasileira, 2005, 29, 2, 293-297.

Rosa, J.M.; Westerich, J.N.; Wilcken, S.R.S. Reprodução de Meloidogyne javanica em olerícolas e em plantas utilizadas na adubação verde. Tropical Plant Pathology, 2013, 133-141.

Santos, H.S.; Scapim, C.A.; Maciel, S.L.; Vida, J.B.; de Freitas Schwan-Estrada, K.R.; Brandão Filho, J.U.T. Patogenicidade de Meloidogyne javanica em alface em função do tamanho de células de bandeja e idade de transplante das mudas, Acta Scientiarum Agronomy, 2008, 28: 253-259.

Silva, M.A.D.; Coelho Júnior, L. .; Santos, A. . Vigor de sementes de coentro (Coriandrum satium L.) provenientes de sistemas orgânico e convencional. Revista Brasileira de plantas medicinais, 2012, 14, 192-196. 